\title{
Reversal of Regioselectivity in Reactions of Donor-Acceptor Cyclopropanes with Eelectrophilic Olefins
}

\author{
Joanna Turkowska, ${ }^{[a],+}$ Jakub Durka, ${ }^{[a],+}$ Michał Ociepa, ${ }^{[a]}$ and Dorota Gryko*[a] \\ Dedicatied to prof. Janusz Jurczak on the occasion of his 80th birthday
}
[a] J. Turkowska, J, Durka, Dr M. Ociepa, Prof. D. Gryko
Institute of Organic Chemistry
Polish Academy of Sciences
Kasprzaka 44/52, 01-224 Warsaw, Poland
E-mail: dgryko@icho.edu.pl
$+\quad$ These authors contributed equally.

Supporting information for this article is given via a link at the end of the document.

\begin{abstract}
Cyclopropanes bearing donor and acceptor groups at the opposite ends of the C-C bond should react with both nucleophiles and electrophiles. Their reactivity towards nucleophiles is well explored while only few specific electrophilic reagents give desired products. These methods are limited by the specific philicity of the carbon atoms resulting from the strong polarization of the central $\mathrm{C}-\mathrm{C}$ bond. Herein, we report that vitamin $B_{12}$ catalysis enables the transformation of initially electrophilic center into a nucleophilic radical that as such reacts with SOMOphiles. This radical-based strategy reverses the standard regioselectivity and thus complements the classical approaches.
\end{abstract}

\section{Introduction}

The chemistry of donor-acceptor (D-A) cyclopropanes (DAC) has experienced a welldeserved revival over the last few years. These compounds are appreciated building blocks offering multifaceted reactivity. ${ }^{[1]}$ Being the smallest cycloalkanes, cyclopropanes are characterized by high ring strain resulting in increased energy; [2] this, however, is not the only factor affecting their chemical properties. An additional activation stems from strong polarization of the C-C bond vicinally substituted with donor and acceptor groups. ${ }^{[16]}$ The zwitterionic relationship between two substituted carbon atoms makes D-A cyclopropanes perfect substrates for cycloadditions, ${ }^{[3]}$ rearrangements ${ }^{[4]}$ and ring opening ${ }^{[5]}$ reactions. The latter provides convenient access to mono- or 1,3-difunctionalized compounds.

As a consequence of the dipole-like nature of DACs, their transformations are highly regioselective. The nucleophilic attack occurs on the donor-substituted carbon atom with a partial positive charge leading to the ring-opening (Scheme $1 \mathrm{~A}) \cdot{ }^{[\mathrm{b}]}$ Subsequently, the negative charge on the carbon bearing the acceptor is neutralized by an electrophile, often a proton, though a number of 1,3-bisfunctionalization reactions have also been reported in the last few years. ${ }^{[6]}$ Exclusively installing an electrophile in the regioselective ring-opening is highly underdeveloped and typically occurs on the acceptor-substituted carbon atom. The only exception to this rule is transition-metal catalyzed addition of C-electrophiles on the donor-substituted carbon atom resulting from the formation of nucleophilic $\pi$-allyl-metal complex. ${ }^{[7,8]}$ The scope 
of this method is, however, limited only to a few vinylcyclopropanes. Consequently, the range of such functionalized derivatives is restricted. To expand synthetic possibilities in this context, we wondered whether it is possible to establish a general method for reversal of the reactivity of the substituted $\mathrm{C}-\mathrm{C}$ bond and hence enable the comprehensive regioselective reaction with electrophilic reagents at the donorsubstituted carbon atom. Based on our experience in Co-catalysis, we thought that it should be an excellent tool for that purpose (Scheme 1B, C). Among cobalt catalysts, vitamin $B_{12}(\mathbf{1}$, cobalamin) offers some exceptional features. In the Co(I) form, it acts as a 'supernucleophile' inclined to react with carbon electrophiles, typically via the $\mathrm{S}_{\mathrm{N}} 2$ mechanism.

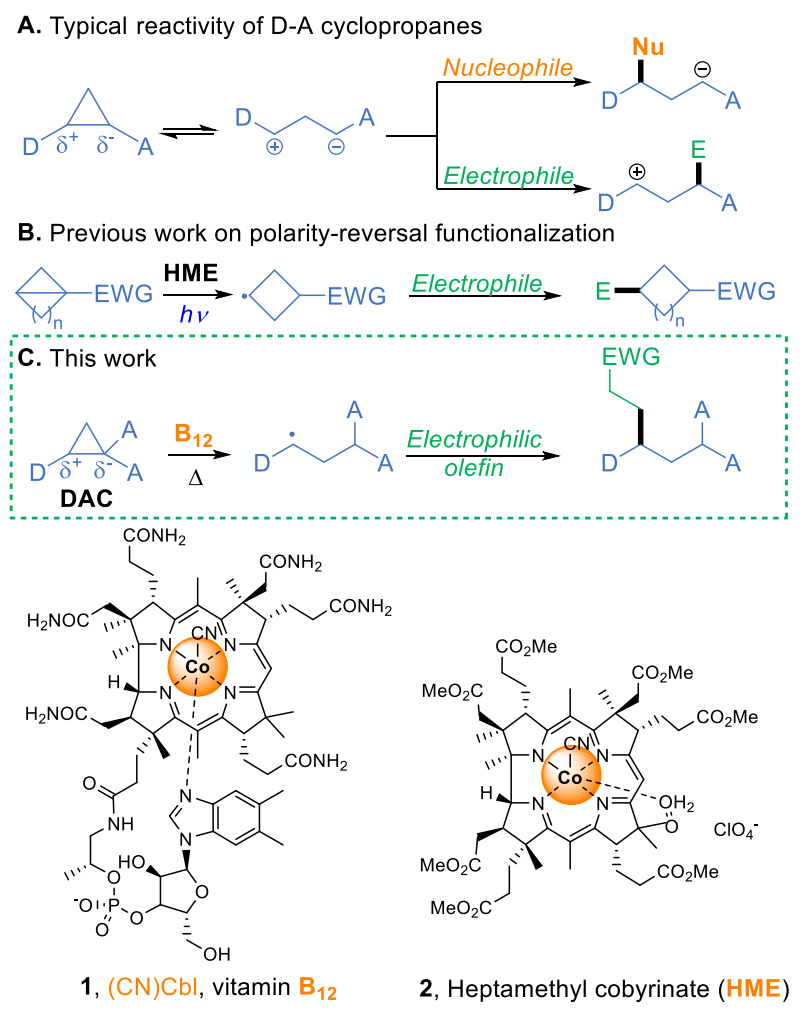

Scheme 1. Reactivity of D-A cyclopropanes.

The newly formed $\mathrm{Co}$ (III)-C bond is prone to homolytic cleavage under both photolytic and thermal conditions giving radicals that subsequently may engage in numerous transformations. ${ }^{[9]}$ In this line, we have employed vitamin $\mathrm{B}_{12}$ for the generation of cyclobutyl and cyclopentyl radicals from bicyclo[1.1.0]butanes and bicyclo[1.1.0]pentanes respectively, involving cleavage of their central C-C bond. ${ }^{[10]}$ This polarity reversal strategy enables reactions with electrophiles and SOMOphiles on the originally electrophilic carbon atom (Scheme 1B). That is possible due to a set of features typical of small bicyclic compounds. They are characterized by high ring strain and their central bridging bonds are polarized when substituted with at least an electron-withdrawing group on one of the bridgehead carbons. ${ }^{[1,11]}$ These properties are also relevant to D-A cyclopropanes, therefore we envisaged that the $\mathrm{B}_{12}$-based methodology can be employed to generate $\mathrm{C}$-centered radicals from this cyclic 
compounds and achieve the addition of SOMOphiles on the donor-substituted carbon atom. The use of electrophilic coupling partner would enable formal electrophileelectrophile coupling expanding the scope of scaffolds accessible from DAC. Scattered information on the ring-opening of cyclopropanes and formation of alkyl-cobalamin derivatives support our hypothesis. ${ }^{[12,13]}$ Recently, we have also used this approach for regioselective ring-opening arylation of epoxides. ${ }^{[14]}$ Our approach would also contribute to the radical chemistry of D-A cyclopropanes which has been recently explored by Werz group. ${ }^{[6 \mathrm{~g}]}$

Herein, we report a polarity-reversal ring-opening alkylation of donor-acceptor cyclopropanes with electrophilic olefins.

\section{Results and Discussion}

We initiated our studies by reacting D-A cyclopropane 3 with Michael acceptor 4 a in the presence of vitamin $\mathrm{B}_{12}(\mathbf{1})$ as a cobalt catalyst and $\mathrm{Zn} / \mathrm{NH}_{4} \mathrm{Cl}$ as a reducing system under blue light irradiation (455 nm, Table 1).

Table 1. Background studies for the model reaction. ${ }^{[a]}$

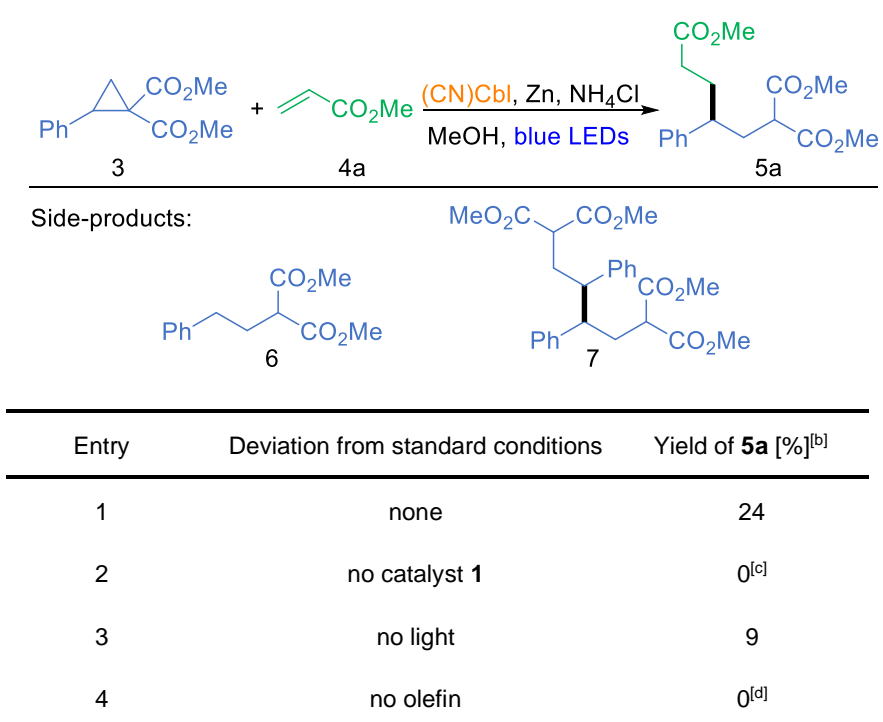

[a] Reaction conditions: DAC 3 ( $0.1 \mathrm{mmol})$, olefin 4a (1.5 equiv), $(\mathrm{CN}) \mathrm{Cbl}(1)(6 \mathrm{~mol} \%), \mathrm{Zn}$ (6 equiv), $\mathrm{NH}_{4} \mathrm{Cl}$ ( 3 equiv), $\mathrm{MeOH}(c=$ $0.1 \mathrm{M}$ ), blue LEDs (455 nm, $9 \mathrm{~W}), 18 \mathrm{~h}$, rt, degassed. (see SI). [b] GC yield. [c] Product 6 was observed. [d] Products 6 and 7 were observed.

The initial conditions afforded product 5 a in $24 \%$ yield (entry 1). Background experiments revealed the crucial role of cobalamin 1 (entry 2). Interestingly, without irradiation, the reaction was not completely halted which suggested thermal conditions might be also suitable for the generation of alkyl radicals (entry 3).

Based on our previous experience, ${ }^{[10,14]}$ it can be reasonably assumed that under the applied conditions, the Co(III) form of the catalyst is reduced to the 'supernucleophilic' $\mathrm{Co}(\mathrm{I})$ species that attacks the donor-substituted carbon atom of DAC generating alkyl radical $\mathbf{B}$ (trapped with TEMPOL, see SI) (Scheme 2). In the desired scenario, it reacts 
with activated olefin affording intermediate $\mathbf{E}$ that after reduction forms desiresd alkylated product $\mathbf{F}$ (Scheme 2 ). In our preliminary experiments, we identified two side products 6 and 7 , which presumably originate from the same radical B. In the first scenario, it is reduced to side-product $\mathbf{C}$. The second option involves dimerization of radical $\mathbf{C}$ leading to dimer $\mathbf{D}$. To corroborate the radical pathway, we performed the model reaction with the addition of (2,2,6,6-tetramethylpiperidin-1-yl)oxyl (TEMPO). When added at the beginning of the reaction, it suppressed the formation of product 5 a completely while its addition after 4 hours diminished yield of product 5 a $(31 \%$, see $\mathrm{SI})$.

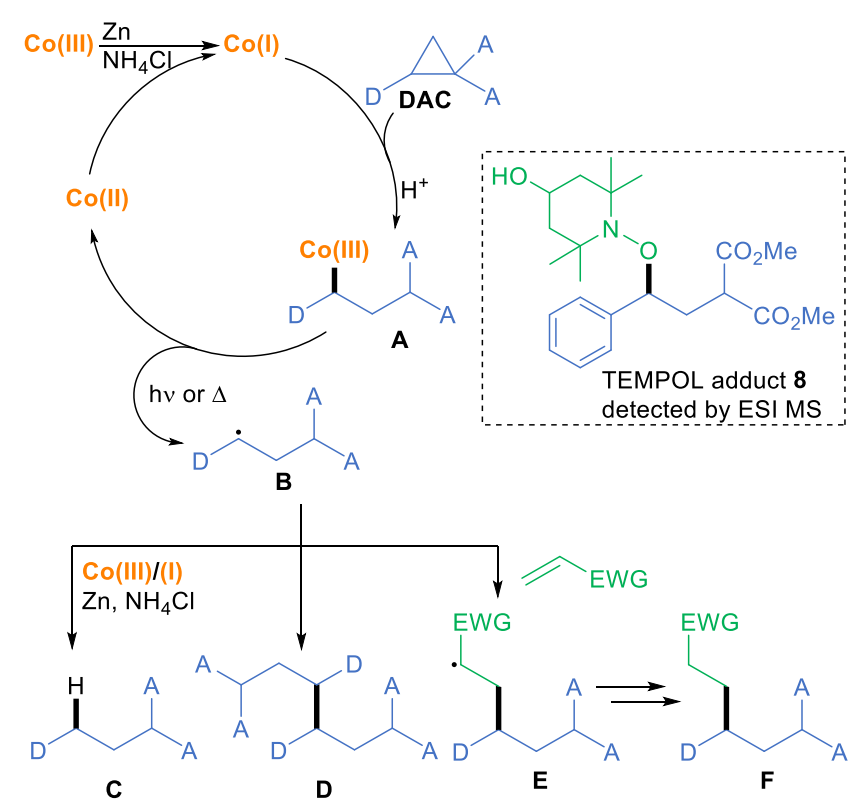

Scheme 2. Plausible pathway of the polarity-reversal alkylation of DAC.

From the beginning of our optimization studies, it became clear that the choice of a solvent is crucial (Table 2). $\mathrm{MeOH}$ gave significantly better results than any other tested, presumably because of the excellent solubility of vitamin $B_{12}$ (1) whilst simultaneously being a source of protons. Since cyanocobalamin (1) and cobalaminbased catalysts 2, 9 were similarly effective (entries 1-3), commercially available, native vitamin $B_{12}$ (1) was further explored. Possible dimerization of a radical derived from cyclopropane $\mathbf{3}$ called for an excess of acceptor $\mathbf{4 a}$ to be used (entry 4 ). The yield of the reaction appreciably increased by the addition of water (5 equiv). One of the most important factors we analyzed was the driving force for the cleavage of the Co-C bond with the concominat formation of $\mathrm{C}$-radicals. Light sources differing in wavelength and power were tested but photochemical conditions, at best gave similar results to those obtained without any irradiation (entry 6$)$. The reaction at slightly elevated temperature $\left(30^{\circ} \mathrm{C}\right)$ was the most effective (entry $\left.1,79 \%\right)$. 
Table 2. Optimization studies. ${ }^{[a]}$

\begin{tabular}{|c|c|c|}
\hline Entry & Deviation from standard conditions & Yield of $5 a[\%]^{[b]}$ \\
\hline 1 & None & $77(79 \%)^{[c]}$ \\
\hline $2^{[d]}$ & HME (2) & 66 \\
\hline $3^{[d]}$ & $\mathrm{Cbl}\left(\mathrm{OH}_{2}\right)^{+} \mathrm{Cl}-9$ (see SI) & 74 \\
\hline 4 & 3 equiv. of $5 \mathbf{a}$ & 63 \\
\hline 5 & no $\mathrm{H}_{2} \mathrm{O}$ & 61 \\
\hline $6^{[e]}$ & Blue LEDs instead of heating & 73 \\
\hline 7 & Room temperature $\left(23^{\circ} \mathrm{C}\right)$ & 62 \\
\hline
\end{tabular}

With the optimized conditions in hand, we explored the substrate scope of the ringopening polarity-reversal alkylation of DAC (Scheme 3). A range of cyclopropanes differing in donor and acceptor groups were reacted with methyl acrylate (4a).

Our method worked well for the substrates bearing aryl substituents at the donor position and the best results were achieved for those with both weakly and strongly electron-donating groups such as phenyl (5a, 79\%), 4-tBu-phenyl (11a, 75\%) and 4OMe-phenyl (10a, 73\%). Substitution at the position 2 of the phenyl ring hinders the attack of the $\mathrm{Co}(\mathrm{I})$ catalyst thus slowing down the desired reaction and diminishing the yield of product 14a (46\%). This problem was, however, easily solved, simply by prolonging the reaction time $(60 \%)$. On the other hand, for cyclopropanes bearing electron-deficient aromatic groups the yields of the products 12a, 13a slightly deminished. In these cases, the presence of a strong electron-withdrawing group at the aromatic ring raises the reduction potential of DAC (see SI for more information) and consequently accelerates side-reactions (ring-opening and reduction of the cyclopropane). These processes should be suppressd for better SOMOphiles which react faster with radicals. Indeed, the use of acrylonitrile, particularly in the case of DAC bearing electron-deficient aromatic substituents, appreciably increased yields of products (Scheme 4, 12b, 13b). 


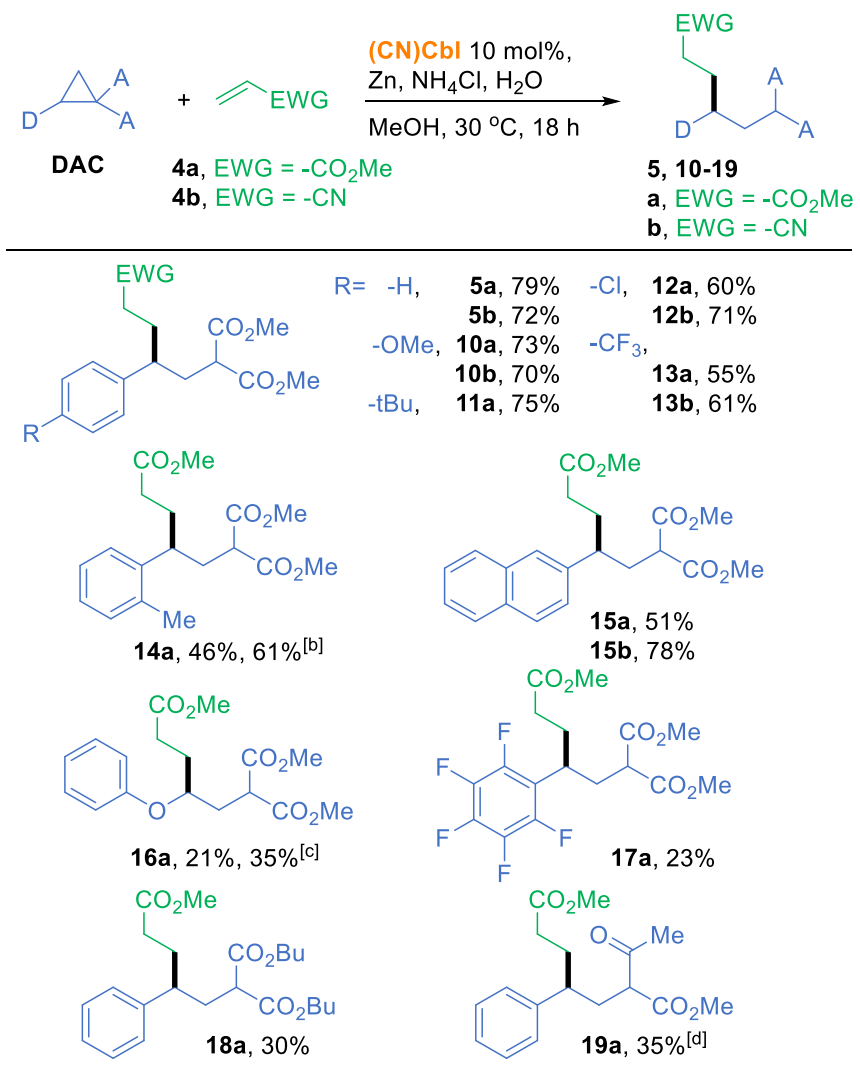

Scheme 3. Scope of reaction: donor-acceptor cyclopropanes. ${ }^{[a]}$ [a] Reaction conditions: DAC (0.2 mmol), olefin 4a or 4b (5 equiv), (CN)Cbl (1, 10 mol\%), $\mathrm{Zn}$ (3 equiv), $\mathrm{NH}_{4} \mathrm{Cl}$ (1.5 equiv), $\mathrm{H}_{2} \mathrm{O}$ (5 equiv), $\mathrm{MeOH}(c=0.2 \mathrm{M}), 30{ }^{\circ} \mathrm{C}, 18 \mathrm{~h}$, degassed. [b] Reaction prolonged to $48 \mathrm{~h}$. [c] Reaction conditions: DAC (0.2 mmol), olefin $\mathbf{4 a}$ or $\mathbf{4 b}$ (5 equiv), $\mathrm{HME}(\mathbf{2}, 5 \mathrm{~mol} \%), \mathbf{Z n}(3 \mathrm{equiv}), \mathrm{NH} \mathrm{Cl}(1.5$ equiv), $\mathrm{MeOH}(c=0.2 \mathrm{M}), 30^{\circ} \mathrm{C}, 18 \mathrm{~h}$, degassed (see $\left.\mathrm{SI}\right)$. [d] a mixture of diastereomers $(47: 53)$.

Next, a set of electrophilic alkenes were tested (Scheme 4). 


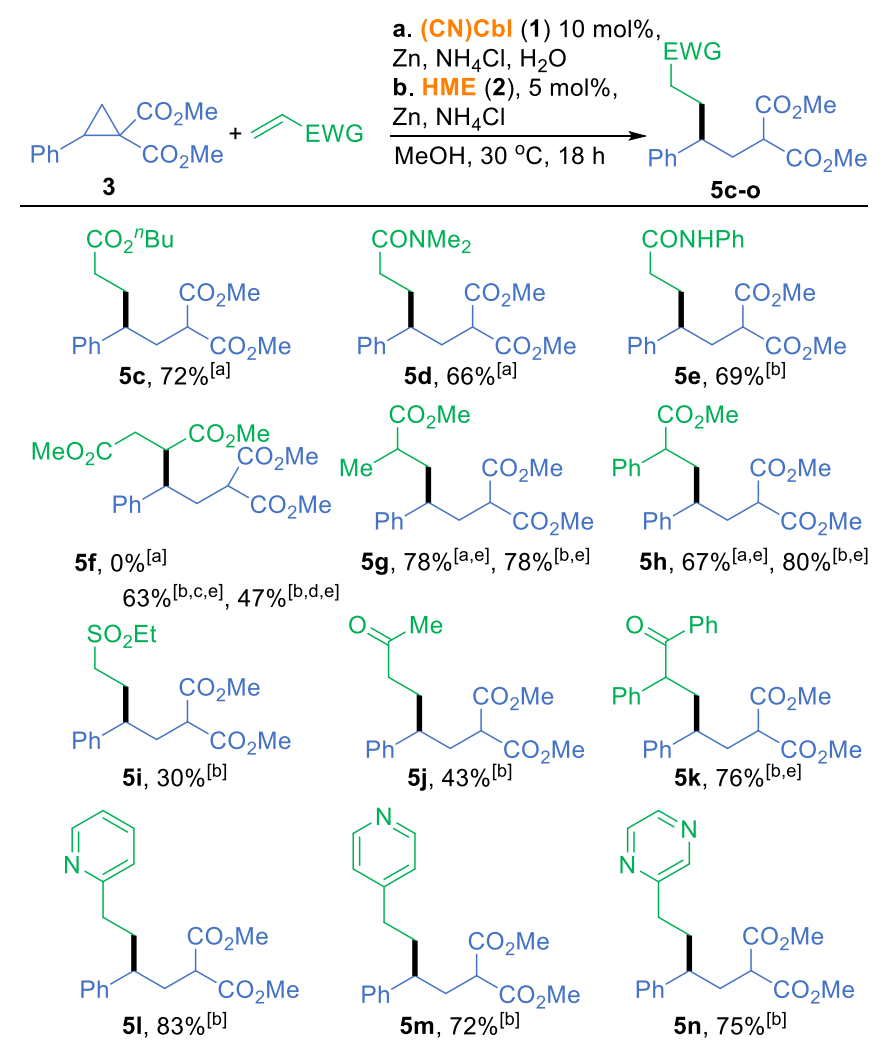

Scheme 4. Scope of reaction: electrophilic alkenes. ${ }^{[a]}$ [a] Reaction conditions a: cyclopropane 3 (0.2 mmol), olefin (5 equiv), (CN)Cbl (1, $10 \mathrm{~mol} \%), \mathrm{Zn}$ (3 equiv), $\mathrm{NH}_{4} \mathrm{Cl}$ (1.5 equiv), $\mathrm{H}_{2} \mathrm{O}$ (5 equiv), $\mathrm{MeOH}(c=0.2 \mathrm{M}), 30^{\circ} \mathrm{C}, 18 \mathrm{~h}$, degassed. [b] Reaction conditions b: cyclopropane 3 ( $0.2 \mathrm{mmol}$ ), olefin (5 equiv), $\mathrm{HME}(2,5 \mathrm{~mol} \%), \mathrm{Zn}$ (3 equiv), $\mathrm{NH}_{4} \mathrm{Cl}$ (1.5 equiv), $\mathrm{MeOH}(c=0.2 \mathrm{M})$, $30{ }^{\circ} \mathrm{C}, 18 \mathrm{~h}$, degassed [c] from dimethyl fumarate; [d] from dimethyl maleate; [e] a mixture of diastereomers.

Various olefins bearing electron-withdrawing groups, including esters $(\mathbf{5 c}, \mathbf{5 g}-\mathbf{h})$, amides $(\mathbf{5 d}, \mathbf{e})$, and nitrile $(\mathbf{5 b})$ are well tolerated. Only traces of product $\mathbf{5 f}$, however, were observed in the case of dimethyl fumarate, which we associated with fast, partial reduction of the olefin under the developed conditions. Hence, changing the kinetics of the desired reaction should eliminate the problem. Our previous studies indicated that the rate of reactions catalyzed by HME (2) are significantly higher than those catalyzed by native vitamin $B_{12 .} .^{[15]}$ Indeed, kinetic studies performed for the HME-catalyzed formation of products $\mathbf{5 a}$ indicated a significant acceleration of the reaction rate compared to (CN)Cbl-catalyzed transformations (Figure 1).

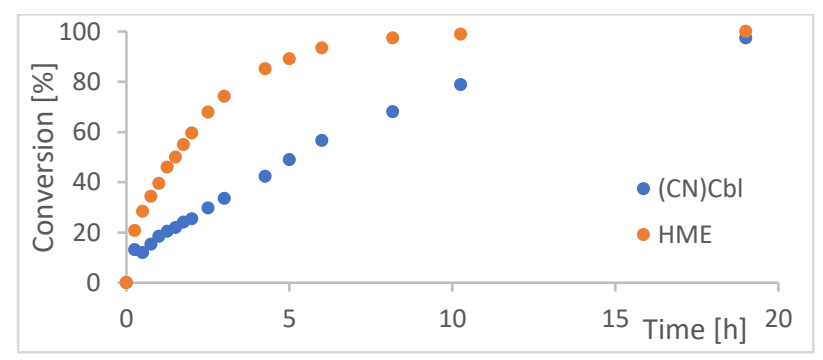

Figure 1. Kinetic profile of the conversion of D-A cyclopropane 3 under model reaction conditions with vitamin $B_{12}(\mathbf{1})$ and $H M E$ (2). 
Indeed, the change of a catalyst from vitamin 1 to HME (2) enabled the formation of product $\mathbf{5} \boldsymbol{f}$ in a satisfactory yield $(63 \%)$. This modified conditions proved also more efficient for other 1,1- and 1,2-disubstituted olefins (5h, 5k) as well as for vinyl ethyl sulfone (5i) or vinyl pyridines and 2-vinylpyrazine giving products $5 \mathbf{5}-\mathbf{m}$ and $\mathbf{5 n}$ in high yields.

\section{Conclusion}

In summary, we have developed a strategy that reverses the reactivity of D-A substituted cyclopropanes, enabling regioselective installation of electrophilic reagent at the originally electrophilic carbon atom. In particular, vitamin $\mathrm{B}_{12}(\mathbf{1})$ as a catalyst reacts with DACs giving alkyl cobalamis. Homolytic cleavage of the $\mathrm{Co}-\mathrm{C}$ bond leads to $\mathrm{C}$-centered radicals that engage in reactions with SOMOphiles. The outcome of the reaction stems from the subtle balance between three competing transformations of the generated radical.

Importantly, the presented strategy complements the existing activation modes for the generation of radicals from donor-acceptor cyclopropanes. Only recently the Werz group reported that the electrocatalytic activation enables generation of a radical on the acceptor-substituted carbon atom in contrast to our B ${ }_{12}$-catalysis. ${ }^{[6 g]}$ As a consequence new molecular scaffolds can be access complementing the library of building-blocks derived from cyclopropanes. We believe it will make a meaningful contribution to expanding the currently available chemical space.

\section{Acknowledgements}

We thank prof. Piotr Lodowski for his comments on the proposed mechanism. Financial support for this work was provided by the Foundation for Polish Sciences (FNP TEAM POIR.04.04.00-00-4232/17-00) and National Science Centre (JT, grant UMO2019/33/N/ST4/01132).

\section{Conflict of Interest}

The authors declare no conflict of interest.

Keywords: cobalamins $\bullet$ Co-catalysis $\cdot$ cyclopropanes $\cdot$ donor-acceptor systems $•$ ring opening

[1] For reviews see: a) H. U. Reissig, R. Zimmer, Chem. Rev. 2003, 103, 1151-1196; b) T. F. Schneider, J. Kaschel, D. B. Werz, Angew. Chemie - Int. Ed. 2014, 53, 5504-5523; c) M. A. Cavitt, L. H. Phun, S. France, Chem. Soc. Rev. 2014, 43, 804-818; d) H. K. Grover, M. R. Emmett, M. A. Kerr, Org. Biomol. Chem. 2015, 13, 655-671; e) N. R. O'Connor, J. L. Wood, B. M. Stoltz, Isr. J. Chem. 2016, 56, 431-444; f) E. M. Budynina, K. L. Ivanov, I. D. Sorokin, M. Y. 
Melnikov, Synth. 2017, 49, 3035-3068; g) O. A. Ivanova, I. V. Trushkov, Chem. Rec. 2019, 19, 2189-2208; h) K. Ghosh, S. Das, Org. Biomol. Chem. 2021, 19, 965-982.

[2] K. B. Wiberg, Angew. Chem. Int. Ed. English 1986, 25, 312-322.

[3] For selected examples see: a) W. D. Mackay, M. Fistikci, R. M. Carris, J. S. Johnson, Org. Lett. 2014, 16, 1626-1629; b) H. Xu, J. L. Hu, L. Wang, S. Liao, Y. Tang, J. Am. Chem. Soc. 2015, 137, 8006-8009; c) L. K. B. Garve, M. Petzold, P. G. Jones, D. B. Werz, Org. Lett. 2016, 18, 564-567; d) L. K. B. Garve, M. Pawliczek, J. Wallbaum, P. G. Jones, D. B. Werz, Chem. - A Eur. J. 2016, 22, 521-525; e) A. U. Augustin, M. Sensse, P. G. Jones, D. B. Werz, Angew. Chem. Int. Ed. 2017, 56, 14293-14296; Angew. Chemie 2017, 129, 14481-14485 f) A. O. Chagarovskiy, V. S. Vasin, V. V. Kuznetsov, O. A. Ivanova, V. B. Rybakov, A. N. Shumsky, N. N. Makhova, I. V. Trushkov, Angew. Chem. - Int. Ed. 2018, 57, 10338-10342; Angew. Chem. 2018, 130, 1049510499; g) A. U. Augustin, M. Busse, P. G. Jones, D. B. Werz, Org. Lett. 2018, 20, 820-823; h) M. Petzold, P. G. Jones, D. B. Werz, Angew. Chem. Int. Ed. 2019, 58, 6225-6229; Angew. Chem. 2019, 131, 6225-6229; i) A. U. Augustin, J. L. Merz, P. G. Jones, G. Mlostoń, D. B. Werz, Org. Lett. 2019, 21, 9405-9409; j) A. Jacob, P. G. Jones, D. B. Werz, Org. Lett. 2020, 22, $8720-$ $8724 ;$ k) G. Nie, X. Huang, Z. Wang, D. Pan, J. Zhang, Y. R. Chi, Org. Chem. Front. 2021, DOI 10.1039/d1qo00826a.

[4] For selected examples see: a) D. R. Wenz, J. R. De Alaniz, Org. Lett. 2013, 15, 3250-3253; b) J. Kaschel, T. F. Schneider, P. Schirmer, C. Maaß, D. Stalke, D. B. Werz, Eur. J. Org. Chem. 2013, 12, 4539-4551; c) H. Chen, J. Zhang, D. Z. Wang, Org. Lett. 2015, 17, 2098-2101.

[5] For selected examples see: a) O. Lifchits, A. B. Charette, Org. Lett. 2008, 10, 2809-2812; b) Q. K. Kang, L. Wang, Q. J. Liu, J. F. Li, Y. Tang, J. Am. Chem. Soc. 2015, 137, 14594-14597; c) K. L. Ivanov, E. V. Villemson, E. M. Budynina, O. A. Ivanova, I. V. Trushkov, M. Y. Melnikov, Chem. - A Eur. J. 2015, 21, 4975-4987; d) A. Lücht, L. J. Patalag, A. U. Augustin, P. G. Jones, D. B. Werz, Angew. Chem. - Int. Ed. 2017, 56, 10587-10591; Angew. Chem. 2017, 129, $10723-$ 10727; e) E. Richmond, V. D. Vuković, J. Moran, Org. Lett. 2018, 20, 574-577; f) A. A. Akaev, M. Y. Melnikov, E. M. Budynina, Org. Lett. 2019, 21, 9795-9799.

[6] For selected examples see: a) L. K. B. Garve, P. Barkawitz, P. G. Jones, D. B. Werz, Org. Lett. 2014, 16, 5804-5807; b) S. Das, C. G. Daniliuc, A. Studer, Org. Lett. 2016, 18, 5576-5579; c) S. Das, C. G. Daniliuc, A. Studer, Angew. Chem. Int. Ed. 2017, 56, 11554-11558; Angew. Chem. 2017, 129, 11712-11716; d) L. K. B. Garve, P. G. Jones, D. B. Werz, Angew. Chem. Int. Ed. 2017, 56, 9226-9230; Angew. Chem. 2017, 129, 9354-9358; e) A. U. Augustin, P. G. Jones, D. B. Werz, Chem. - A Eur. J. 2019, 25, 11620-11624; f) A. Guin, T. Rathod, R. N. Gaykar, T. Roy, A. T. Biju, Org. Lett. 2020, 22, 2276-2280; g) S. Kolb, M. Petzold, F. Brandt, P. G. Jones, C. R. Jacob, D. B. Werz, Angew. Chem. Int. Ed. 2021, 60, 15928-15934; Angew. Chem. 2021, 133, 16064-16070.

[7] N. Selander, K. J. Szabó, Chem. Commun. 2008, 3420-3422.

[8] J. Moran, A. G. Smith, R. M. Carris, J. S. Johnson, M. J. Krische, J. Am. Chem. Soc. 2011, 133, 18618-18621.

[9] a) M. Giedyk, K. Goliszewska, D. Gryko, Chem. Soc. Rev. 2015, 44, 3391-3404; b) K. L. Brown, Chem. Rev. 2005, 105, 2075-2149; c) M. Hapke, G. Hilt, Cobalt Catalysis in Organic Synthesis, Wiley-VCH, 2020.

[10] M. Ociepa, A. J. Wierzba, J. Turkowska, D. Gryko, J. Am. Chem. Soc. 2020, 142, 5355-5361.

[11] J. Turkowska, J. Durka, D. Gryko, Chem. Commun. 2020, 56, 5718-5734.

[12] Y. Hisaeda, T. Nishioka, Y. Inoue, K. Asada, T. Hayashi, Coord. Chem. Rev. 2000, 198, 21-37.

[13] T. Troxler, R. Scheffold, Helv. Chim. Acta 1994, 77, 1193-1202.

[14] a) A. Potrząsaj, M. Musiejuk, W. Chaładaj, M. Giedyk, D. Gryko, J. Am. Chem. Soc. 2021, 143, 9368-9376; b) A. Potrząsaj, M. Ociepa, O. Baka, G. Spólnik, D. Gryko, Eur. J. Org. Chem. 2020, 2020, 1567-1571. 
[15] M. Karczewski, M. Ociepa, K. Pluta, K. ó Proinsias, D. Gryko, Chem. - A Eur. J. 2017, 23, 70247030. 